\title{
Photovoltaic panels tilt angle optimization
}

\author{
Kerry A. Sado ${ }^{1 *}$, Lokman H. Hassan ${ }^{2}$, and Shivan Sado \\ ${ }^{1}$ University of Duhok, Electrical and Computer Engineering, Duhok, Kurdistan Region, Iraq. \\ kherysado@yahoo.com/kerry.sado@uod.ac \\ ${ }^{2}$ University of Duhok, Electrical and Computer Engineering, Duhok, Kurdistan Region, Iraq. \\ lokman.hadi@uod.ac \\ ${ }^{3}$ University of Nebraska-Lincoln, Electrical \& Computer Engineering, Lincoln, NE, USA. \\ shivansado@yahoo.com/ ssado2@unl.edu
}

\begin{abstract}
The tilt angle of solar panels is significant for capturing solar radiation that reaches the surface of the panel. Photovoltaic (PV) performance and efficiency are highly affected by its angle of tilt with respect to the horizontal plane. The amount of radiation reaching the surface of a PV panel changes with the changes in its tilt angle, hence adding a solar tracking system will maximize the amount of solar radiation reaching the surface of a PV panel at any time during the day, however, integrating solar tracking system will increase the total cost and maintenance of any PV system. Thus, using an optimized fixed tilt angle is the solution to element the initial, maintenance, and operation costs of a solar tracking system. Yet, the fixed angle is location-specific because it depends on the daily, monthly, and yearly location of the sun. In this study; daily, monthly and seasonally angles are calculated mathematically and the amount of incident radiation on the surface of the PV panel is measured along with its voltage. By comparing the practical measurements of the output voltage of PV panels, an optimized tilt angle is decided.
\end{abstract}

Keywords- Tilt Angle, PV cell, Solar Panel, renewable energy.

\section{Introduction}

The new modern world is currently moving from conventional energy sources to the clean and renewable ones. Solar energy has been known as one of the most promising and reliable renewable energy sources, since it is sustainable and accessible almost everywhere around the world. One promising application of solar energy is Photovoltaic (PV) technology which has developed rapidly. Solar PV technology is one of the best methods to harness solar power [1]. The annual solar energy reaching on the surface of the earth is $1.5 \times 1018 \mathrm{kWh}$ [2], about $30 \%$ of the incoming energy is reflected back to space while the rest is absorbed by oceans, land masses and clouds. Iraq is located in the Middle East between latitudes $29^{\circ} 5^{\prime}$ and $37^{\circ} 22^{\prime} \mathrm{N}$ and longitudes $38^{\circ} 45^{\prime}$ and $48^{\circ} 45^{\prime} \mathrm{E}$. The highest solar radiation is estimated at $6790 \mathrm{kWh} / \mathrm{m} 2$ in September, while the lowest is $1660 \mathrm{kWh} / \mathrm{m} 2$ in December [3]. Therefore, Iraq is well located in terms of solar energy potential.

\footnotetext{
*Corresponding author: kherysado@yahoo.com/ Kerry.sado@uod.ac
} 
The performance of PV panels is highly affected by its orientation and tilting angle. The tilt angle and orientation can change the amount of solar radiation captured by the panel.

Maximum daily energy can be collected by using solar tracking systems also some fixed systems based on the daily, weekly monthly and seasonally optimized tilt angle at particular geographical locations. The radiation level reaching the panels depends on the latitude and longitude of the location where PV panels are located. While sun beams fall with the steep angle at noon, they fall with a narrow angle in the mornings and afternoon. Hence PV tilt angles varies depending on the location, and they differ monthly, seasonally and yearly [4]. Monthly and seasonal changes of tilt angles of panels should be considered by mathematical calculations and supported by experimental results. Many studies showed that the optimum tilt angle depends on latitude angle $(\lambda)$, solar declination angle or days of the year [5]. Researcher in [6] Calculated the optimum fixed tilt angle of the PV panel in Turkey, they compared the mathematical analysis results with the experimental results. Their experimental results showed a difference of $11^{\circ}$ between the mathematical and experimental results. Researchers [7] Used Google earth and data from NASA website to calculate the optimal tilt angle for Iraq provinces, they indicated that the yearly optimum tilt angle for Duhok is 34.5 . Their study did not include a comparison between mathematical calculations and Google earth results for choosing an optimum tilt angle. In [8], the authors investigated the effect of various tilt angles on the output of a solar panel in Iraq. Their study showed that adjusting tilt angle of a PV panel installed in Iraq eight times a year can capture the same amount of energy as when the tilt angle is adjusted daily. Optimal tilt angle calculation was mathematically formulated in [9] for finding the optimal tilt angle in Syria. It was reported that using 12 intervals during a year approximately result in a maximum solar generation. The rest of the paper is organized as follows: a brief description of tilt angles and PV panels is provided in section 2; Mathematical equations and calculations of tilt angle are provided in section 3; the experimental setup and results discussion are provided in section 4; Section 5 provide results discussion and conclusion.

\section{Tilt angles and PV panels 2.1 PV tilt Angle}

Solar PV tilt angle is defined as the number of degrees from the horizontal plane [10], another definition it is slope angle at which solar panels are mounted to face the sun.

The fixed angle is location specific because it depends on the daily, monthly and yearly location of the sun [11]. [12] Showed that daily changes in tilt angles to their optimum value in Egypt can reach a total annual gain in solar radiation of $29.2 \%$ more than a fixed collector with a tilt angle equal to its geographic latitude. Yet, daily adjustment of tilt angles is not a practical solution, due to frequent changes of the angle and composite structure of frames which support solar panels.

\subsection{PV panels}

PV panels are semiconductor devices that directly convert the sunlight falling on them to electrical energy [13]. The efficiency and performance of PV systems are affected by many factors, such as solar tracking system, shading or partial shading, solar angle, dust, and cell operating temperature. To achieve maximum output power from PV systems, PV panels must be installed with a specific orientation and tilt angle with the horizontal plane. The PV modules are placed facing south in the northern hemisphere as a general rule. A simple equivalent circuit model for a photovoltaic cell consists of a real diode in parallel with an ideal current source as shown in Fig. 1. The ideal current source delivers current in proportion to the solar flux to which it is exposed [14]. 


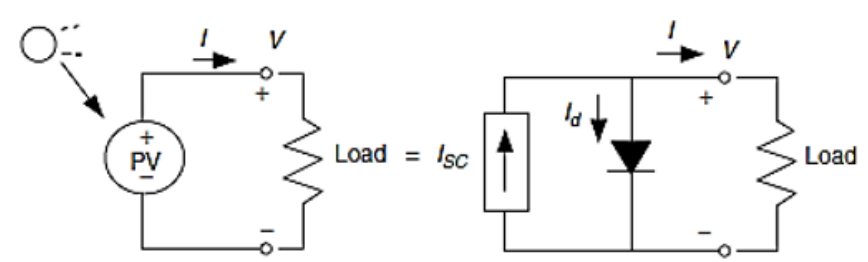

Fig. 1 A simple equivalent circuit for a photovoltaic cell.

\subsection{Mathematical equivalent circuit for photovoltaic array}

The equivalent circuit of a PV cell is shown in Fig. 2. The current source Iph represents the cell photocurrent. Rsh and Rs are the intrinsic shunt and series resistances of the cell, respectively. Generally, the value of Rsh is very large and that of Rs is very small, therefore they may be neglected to simplify the analysis [15]

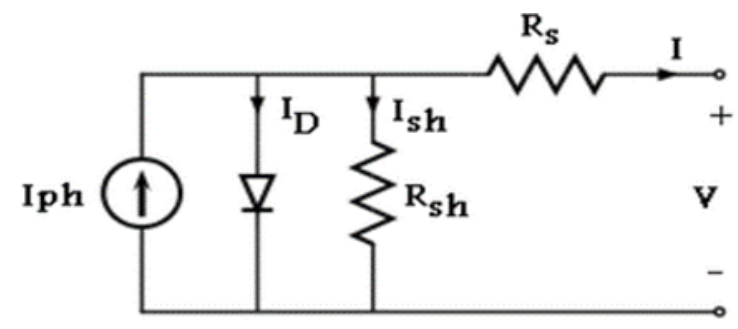

Fig. 2 Equivalent PV cell circuit.

Practically, PV cells are grouped in larger units called PV modules and these modules are connected in series or parallel to create PV arrays which are used to generate electricity in PV generation systems. The equivalent circuit for PV array is shown in Fig. 3.

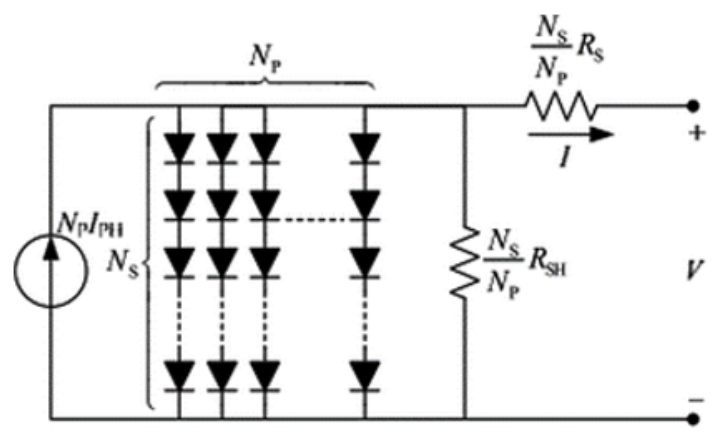

Fig. 3 Equivalent circuit of PV array.

The voltage-current characteristic equation of a solar cell is provided as: Module photocurrent Iph:

$I_{p h}=\left[I_{s c}+K_{i}(T-298)\right] \times I r / 1000$

Where, Iph: photo-current (A); Isc: short circuit current (A); Ki: short-circuit current of cell at $25{ }^{\circ} \mathrm{C}$ and $1000 \mathrm{~W} / \mathrm{m} 2$; T: operating temperature $(\mathrm{K})$; Ir: solar irradiation $(\mathrm{W} / \mathrm{m} 2)$.

The reverse saturation current of the module $I_{r s}$ :

$I_{r s}=I_{s c} /\left[\exp \left(q V_{O C} / N_{S} k n T\right)-1\right]$ 
Where, q: electron charge, $=1.6 \times 10-19 \mathrm{C}$; Voc: open circuit voltage $(\mathrm{V})$; Ns: number of cells connected in series; $\mathrm{n}$ : the ideality factor of the diode; $\mathrm{k}$ : Boltzmann's

constant, $=1.3805 \times 10-23 \mathrm{~J} / \mathrm{K}$. With cell`s temperature variation, the saturation current $\mathrm{I} 0$ is given by:

$I_{0}=I_{r s}\left[\frac{T}{T_{r}}\right]^{3} \exp \left[\frac{q \times E_{g 0}}{n k}\left(\frac{1}{T}-\frac{1}{T_{r}}\right)\right]$

Where, Tr: nominal temperature $=298.15 \mathrm{~K} ; \mathrm{Eg} 0$ : band gap energy of the semiconductor, = $1.1 \mathrm{eV}$; The current output of PV module is:

$$
\begin{aligned}
I= & N_{P} \times I_{p h}-N_{P} \times I_{0} \\
& \times\left[\exp \left(\frac{V / N_{S}+I \times R_{S} / N_{P}}{n \times V_{t}}\right)-1\right]-I_{s h} \\
V_{t}= & \frac{k \times T}{q} \quad \text { and } \quad I_{S h}=\frac{V \times N_{P} / N_{S}+I \times R_{S}}{R_{S h}}
\end{aligned}
$$

Where: Np: number of PV modules connected in parallel; Rs: series resistance $(\Omega)$; Rsh: shunt resistance $(\Omega)$; Vt: diode thermal voltage $(\mathrm{V})$.

\section{MATHEMATICAL CALCULATION OF TILT ANGLE}

The earth orbits the sun in an elliptical way, making one revolution every 365.25 days. For solar energy applications, the characteristics of the earth's orbit are considered to be unchanging [14]. It is known that the sun rises in the east and sets in the west and reaches its highest point sometime in the noon. As shown in Fig. 4, the angle formed between the plane of the equator and a line drawn from the center of the sun to the center of the earth is called the solar declination $\delta[14]$.

On June 21 (the summer solstice) the sun reaches its highest point, and a ray drawn at that time from the center of the sun to the center of the earth makes an angle of $23.45^{\circ}$ with the On June 21 (the summer solstice) the sun reaches its highest point, and a ray drawn at that time from the center of the sun to the center of the earth makes an angle of $23.45^{\circ}$ with the earth's equator. On that day, the sun is directly over the Tropic of Cancer at latitude $23.45^{\circ}$. At the two equinoxes, the sun is directly over the equator. On December 21 the sun is 23.45 o below the equator, which defines the latitude known as the Tropic of Capricorn. Calculation of the optimal tilt angle of a PV panel requires an understanding of the declination angle of the earth. Declination angle varies between the extremes of $\pm 23.45^{\circ}$, and a simple sinusoidal relationship that assumes a 365 -day year and which puts the spring equinox on day $n=81$ provides a very good approximation. Declination angle is calculated by the following equation.

$\delta=23.45^{\circ} \sin \left[\frac{360}{365}(\mathrm{n}-81)\right]$

Where $\mathrm{n}$ is the $\mathrm{nth}$ day of the year, for example, the January $1^{\text {st }}$ is 1 .

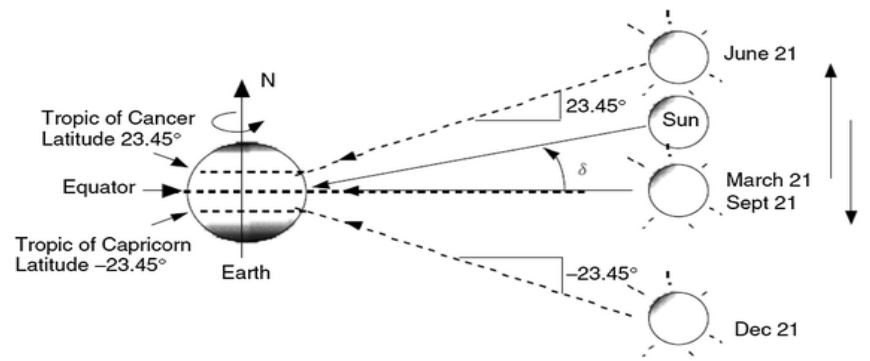

Fig. 4 An alternative view with a fixed earth and a sun that moves up and down. The angle between the sun and the equator is called the solar declination $\delta$ [14]. 
The altitude angle is calculated as:

$$
\beta N=90^{\circ}-L+\delta
$$

where $\mathrm{L}$ is the latitude of the site. The tilt angle that is given by:

$$
\text { Tilt }(\varnothing)=90^{\circ}-\beta N
$$

Equations (5-7) are used to calculate the declination angle and tilt angle for solar PV modules for each day of the year [15]. Using equation (5-7), the tilt angle of the first day of each month in a year for Duhok city written in the Matlab program using the formulas about solar angles is shown in Fig. 5.

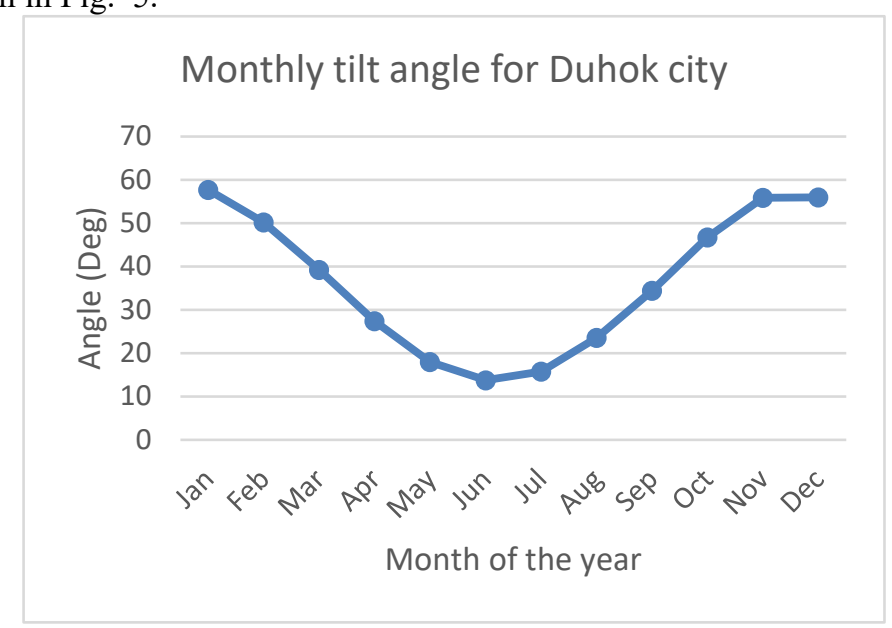

Fig. 5 Monthly tilt angles for Duhok city

The monthly optimum fixed tilt angles are shown in Table 1 .

Table 1: Monthly Optimum Tilt Angle

\begin{tabular}{|l|l|l|l|l|l|}
\hline Jan & Feb & Mar & Apr & May & Jun \\
\hline $57.7^{\circ}$ & $50.18^{\circ}$ & $39.24^{\circ}$ & $27.36^{\circ}$ & $18.0^{\circ}$ & $13.78^{\circ}$ \\
\hline Jul & Aug & Sep & Oct & Nov & Dec \\
\hline $15.75^{\circ}$ & $23.56^{\circ}$ & $34.46^{\circ}$ & $46.7^{\circ}$ & $55.9^{\circ}$ & $55.95^{\circ}$ \\
\hline
\end{tabular}

For maximum efficiency and practical use of fixed tilt angle, the optimum fixed tilt angle is calculated on monthly basis. The yearly tilt angle for Duhok city is calculated at $36.88^{\circ}$ which is nearly equal to the latitude of the city [16].

\section{EXPERIMENTAL METHODOLOGY}

In this study, three identical $100 \mathrm{~W}$ monocrystalline PV panels are used. Each panel is able to produce maximum power (Pmax) of 100 watts at standard conditions (STC) (i.e., temperature $25^{\circ} \mathrm{C}, 1000$ watts $/ \mathrm{m} 2$ of solar insolation and air mass of 1.5$)$. However, in Iraq the operating temperatures during the summer are usually higher than STC. PV panels operating at temperatures higher than $25^{\circ} \mathrm{C}$ produce less than their rated power. Thus, the efficiency of PV panels drops below the rated values. These modules can produce a voltage (Vmp) and current (Imp) of 16.7 volts and 3.0 amps with an efficiency of $13.5 \%$ at STC. The open circuit voltage (Voc) and short-circuit current (Isc) of each module are $21.1 \mathrm{~V}$ and $3.20 \mathrm{~A}$ respectively. Three different tilt angles are calculated mathematically using (5-7): 
1. $14.8^{\circ}$ : optimum tilt angle of the 1 st day of June.

2. $\mathbf{1 3 . 7 8}^{\circ}$ : average angle for the month of June.

3. $\mathbf{2 2}^{\circ}$ : average angle for 4 months (June, July, August, and September).

The panels are tilted with tilt angles of $14.8^{\circ}, 13.78^{\circ}$, and $22^{\circ}$, a digital Multimeter is connected to each panel to record the open circuit voltage of each panel. An Arduino mega microcontroller is programmed to record the voltage produced by each panel over a period of 15 hours, the micro controller is connected to the panels through a voltage sensor, and the voltage of each panel is recorded in a micro-SD card. Different values of PV output voltage are recorded, the values are shown in Fig. . The values of output voltage are recorded for each tilt angle and for different hours of the day. It is shown that the best tilt angle to get maximum output voltage is $14.8^{\circ}$.

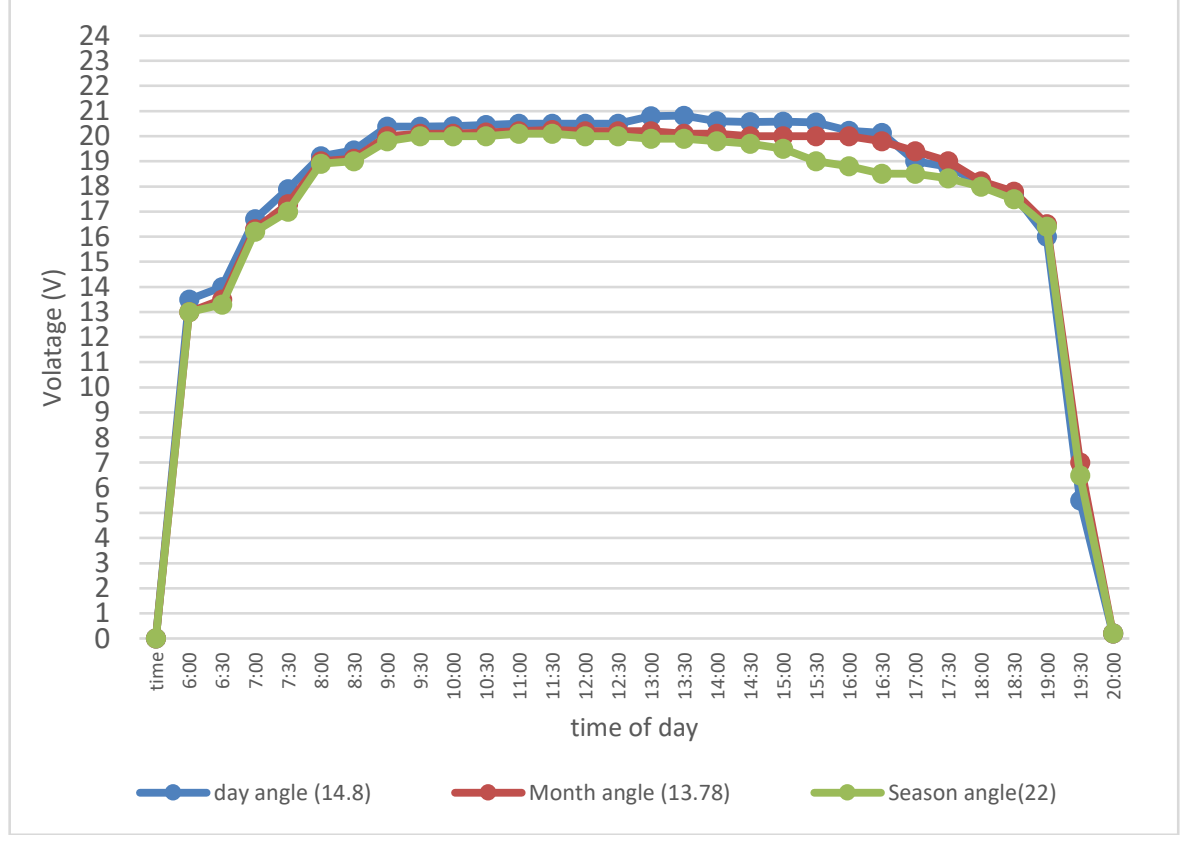

Fig. 6 PV open circuit voltage for different tilt angles

On the other hand, the tilt angle of each panel was adjusted to get the maximum output voltage, it is noticed that the experimental tilt angle differs from the mathematical results by approximately $8^{\circ}$.

\section{CONCLUSIONS}

The fixed tilt angle of photovoltaic panels affects directly on the amount of generated electricity by the panels; therefore, the angles must be identified correctly and accurately to increase the amount of incident solar radiation on the surface of PV panels. When calculating the optimized fixed tilt angle, the results show that the experimental results differ from the mathematical results by approximately $8^{\circ}$. The difference is caused by some environmental factors such as temperature, dust, and dirt. The increase in temperature decreases the voltage of PV panels and so decreases the efficiency of the panels. 


\section{References}

1. H. M. S. Hussein, G. E. Ahmad, and H. H. El-Ghetany, "Performance evaluation of photovoltaic modules at different tilt angles and orientations," Energy Conversion and Management, vol. 45, pp. 2441-2452, (2004/09/01/ 2004).

2. G. Liu, W. Wu, Q. Ge, E. Dai, Z. Wan, and Y. Zhou, "GIS-Based Assessment of Roof-Mounted Solar Energy Potential in Jiangsu, China," in 2011 Second International Conference on Digital Manufacturing \& Automation,pp. 565571 (2011).

3. P. E. S. A. D. Hansen, L. H. Hansen, and H. W. Bindner, "Models for a standalone PV system,", Ris $\phi$ National Laboratory, Roskilde, (December 2000).

4. A. Rouholamini, H. Pourgharibshahi, R. Fadaeinedjad, and G. Moschopoulos, "Optimal tilt angle determination of photovoltaic panels and comparing of their mathematical model predictions to experimental data in Kerman," in 2013 26th IEEE Canadian Conference on Electrical and Computer Engineering (CCECE), pp. 1-4(2013).

5. K. Ulgen, "Optimum Tilt Angle for Solar Collectors," Energy Sources, Part A: Recovery, Utilization, and Environmental Effects, vol. 28, pp. 1171-1180, (2006/09/01 2006).

6. A. Karafil, H. Ozbay, M. Kesler, and H. Parmaksiz, "Calculation of optimum fixed tilt angle of PV panels depending on solar angles and comparison of the results with experimental study conducted in summer in Bilecik, Turkey," in 2015 9th International Conference on Electrical and Electronics Engineering (ELECO),pp. 971-976 (2015).

7. A. H. U. E. J. M. Imad Jawad Khadim, "Determining Tilt Angle for Fixed Solar Panel Tosites of Iraq's Provinces by Using the Programs on NASA and Google Earth Websites," Eng. \&Tech.Journal, vol. 32,pp 1-5 (2013).

8. G. R. Saraf and F. A. W. Hamad, "Optimum tilt angle for a flat plate solar collector," Energy Conversion and Management, vol. 28, pp. 185-191, (1988).

9. F. Safdarian and M. E. Nazari, Optimal tilt angle and orientation for solar collectors in Iran, pp 1-3 (2015).

10. P. Yadav, N. Kumar, and S. S. Chandel, "Simulation and performance analysis of a $1 \mathrm{kWp}$ photovoltaic system using PVsyst," in 2015 International Conference on Computation of Power, Energy, Information and Communication (ICCPEIC), pp. 0358-0363 (2015).

11. K. A. Sado and L. H. Hassan, "Modeling and Implementation of a PV-powered DC Water Pump System for Irrigation in Duhok City," Academic Journal of Nawroz University, pp. 228-235, (2018).

12. A. Gharakhani Siraki and P. Pillay, "Study of optimum tilt angles for solar panels in different latitudes for urban applications," Solar Energy, vol. 86, pp. 1920-1928, (2012).

13. A. George and R. Anto, "Analytical and experimental analysis of optimal tilt angle of solar photovoltaic systems," in 2012 International Conference on Green Technologies (ICGT), pp. 234-239 (2012).

14. G. M. Masters, Renewable and Efficient Electric Power Systems: Wiley-IEEE Press, pp 390-398 (2013). 
15. C. S. SOLANKI, Solar Photovoltaics: Fundamentals, Technologies And Applications: PHI Learning, pp 200-220(2015).

16. K. A. Sado, L. H. Hassan, and M. Moghavvemi, "Design of a PV-powered DC water pump system for irrigation: a case study," in 2018 53rd International Universities Power Engineering Conference (UPEC), pp. 1-6 (2018). 